\title{
Environmental Impact on Biodegradation Speed and Biodegradability of Polyethylene and Zea Mays Starch Blends
}

\author{
Abiodun A. Abioye ${ }^{1 *}$, Oreofe P. Oluwadare², Oluwabunmi P. Abioye1, \\ Chukwunonso C. Obuekwe' ${ }^{1}$, Adeniran S. Afolalu', Pethuel O. Atanda ${ }^{3}$, \\ Muyiwa A. Fajobi ${ }^{1}$ \\ 1 Department of Mechanical Engineering, Covenant University, Cannanland, Ota, 112233, Nigeria \\ 2 Department of Mechanical Engineering, Obafemi Awolowo University, Ile-Ife, 220282, Nigeria \\ 3 Department of Materials Science Engineering, Obafemi Awolowo University, Ile-Ife, 220282, Nigeria \\ * Corresponding author's e-mail: abiodun.abioye1@covenantuniversity.edu.ng
}

\begin{abstract}
Several studies projected that by year 2025, 4.3 billion urban residents will be generating about 2.2 billion tonnes of municipal solid waste per year, over $10 \%$ of which will be plastics. The landfills in Nigeria are uncontrolled and do not conform to the international standards of similar operations elsewhere in the world; this makes the disposal of synthetic polymers in the soil even more hazardous. Due to the availability and relative inexpensiveness of Zea mays in Nigeria, this study explores the use of this natural polymer, blended with low density polyethylene (LDPE) as an alternative to synthetic plastics. Biodegradability of the biopolymer blend was observed while buried in loamy sand soil with properties similar to the soil found in the general area of the study. The results showed that a polymer blend with 50\% LDPE (50 CoS) by weight had the most uniform weight loss over the period of the study. Under the soil conditions given in the study, $50 \mathrm{CoS}$ also had the steadiest rate of degradation. Hence $50 \%$ LDPE (wt.\%) blended with Zea mays starch is the optimal ratio with regard to the degradability of biopolymer in loamy sand soil Ota, Ogun State, Nigeria.
\end{abstract}

Keywords: biodegradable; biodegradation rate; biopolymer; loamy sand; Zea mays

\section{INTRODUCTION}

In 2002, there were 2.9 billion urban residents who generated about $0.64 \mathrm{~kg}$ of municipal solid waste (MSW) per person per day (0.68 billion tonnes per year). Ten years after, the statistics show an increase to about 3 billion residents generating $1.2 \mathrm{~kg}$ per person per day (1.3 billion tonnes per year). It is estimated that by 2025 , there will be about 4.3 billion urban residents generating about $1.42 \mathrm{~kg} / \mathrm{capita} / \mathrm{day}$ of MSW (2.2 billion tonnes per year) according to Hoornweg and Bhada-Tata (2012). Currently, over 10 percent $(10 \%)$ by weight of municipal garbage content in the world are plastics (D'Alessandro, 2014).

Recently, plastics have been in the public eye for potentially dangerous human exposure to such toxic components as bisphenol $\mathrm{A}(\mathrm{BPA})$ and di-(2-ethylhexyl) phthalate (DEHP) as stated by Halden (2010) and Gilpin et al (2003). As a result, an effort is currently being made to reduce to barest minimum (or even phase out), the presence of these toxic components from plastics by exploring biodegradable options for plastic packaging, opportunities for reducing plastic waste, and recycling in the quest to reap maximum benefits from polymers without compromising the human health or the environment in the process (North and Halden, 2013; Westblad et al., 2002; Gregory, 2009).

Research has shown that plastics make up the second highest percentage by weight (18\%) of the MSW composition in Nigeria after organic waste (57\%). Paper makes up $11 \%$, glass $5 \%$, metal $5 \%$ and others (textiles, leather, rubber, multi-laminates, e-waste, appliances, ash, other 
inert materials) $4 \%$. There are four major options for the disposal of plastics: landfilling, incineration, recycling, and biodegradation (Hoornweg and Bhada-Tata, 2012).

All plastics can be disposed of in landfills or incinerated. However, landfills require space. Moreover, the chemical constituents and energy contained in plastic materials is typically lost in this disposal route (Hopewell et al, 2009). In Nigeria, landfills are uncontrolled and do not conform to international standards of similar operations elsewhere in the world (Olorunfemi, 2011).

Several researchers have studied MSW collection and management crisis in Nigerian cities. The majority of this literature revealed the basis for high waste generation, inefficient waste collection and management in urban areas (Agwu, 2012; Igbinomwanhia and Ohwovoriole, 2012; Kayode and Omole, 2011; Ofuani, 2011). Some of the challenges facing waste management in Nigeria have been attributed to lack of awareness, poor public enlightenment, inappropriate technology, education and poverty, among others (Olorunfemi, 2011; Achi et al, 2012; Momoh and Oladebeye, 2010).

This study shows that Zea mays starch, which is a relatively cheap and easy to obtain natural polymer, could be blended with synthetic polymer to enhance degradation. In the event of the disposal of this biopolymer blend in the earth, this study also examines the impact of the soil kind present in the southwestern region of Nigeria (particularly Ogun State) on the biodegradability and rate of biodegradation of Zea mays starch biopolymer blend. Maize is the second most cultivated crop in Nigeria in terms of area harvested (over 5.8 million $\mathrm{Ha}$, second to Cassava with 7.1 million Ha). Nigeria is the second largest maize producer in Africa, after South Africa, with an estimated 10.79 million MT produced in 2014 (Liverpool-Tasie et al., 2017; FAO, 2017; Lamidi, 2013).

Several researchers (Mostafa et al., 2018; Cho et al., 2011; Makhtar et al., 2013) have carried out studies on production and analysis of biodegradable polymers as well as their impact on the environment. Plastics are typically organic polymers of high molecular mass, most commonly derived from petrochemicals, thus making them synthetic (Andrej, 2012). Conversely, a range of variants are made from renewable stock such as polylactic acid from corn or Cellulosics from cotton linters (Mostafa et al.,
2018; Axel, 2009). People have been utilizing naturally derived plastics for far longer than one might envision. For instance, medieval artisans made lantern windows from translucent slices of animal horn, which is composed of keratin - a blended carbon-nitrogen polymer - a similar material that skin and hair, as well as fleece, is made of (Norbert, 1968).

In this research, polymer blend samples from LDPE and Zea mays starch were produced at different compositions and their biodegradation ratio and rate were analysed in sandy loam soil in Ota, Ogun State, Nigeria, over the period of 28 days in order to determine the effect of the soil on the biodegradation properties of the blends.

\section{METHODS}

\section{Materials and apparatus}

About $12 \mathrm{~kg}$ of Low-Density Polyethylene (LDPE) was sourced for this research. The starch used in this project was made from Zea mays. Glycerol was used as the plasticizer. Other materials used included distilled water, paper tape and thread. The utilized cleaning materials included iron sponges and detergent.

The apparatus used for the study comprised; a crucible furnace, stirrer, the OHAUS digital weighing scale (Model PA214), stainless steel wire mesh sieves $(\varnothing 0.08 \mathrm{~mm} / 80 \mu \mathrm{m}$ and Ø $0.2 \mathrm{~mm} / 200 \mu \mathrm{m}$ ), Winkworth Z Blade Sigma industrial blender, beakers, plastic bottles, cutter, trays and aluminium foil sheets.

\section{Soil analysis}

A soil sample from the study area was taken at a depth of $10.16 \mathrm{~cm}$ to determine the particle size composition. Organic matter content (OMC) was determined using the ASTM D-2974- standard test method. The soil temperature was measured by inserting digital thermometer with sensor to obtain precise temperature measurement.

Soil temperatures at a depth of $10.16 \mathrm{~cm}$ were observed twice a day; soil temperature per day was within the range of $23-35^{\circ} \mathrm{C}$.

\section{Starch extraction process}

The process followed for extracting starch from Zea mays is shown in Figure 1 


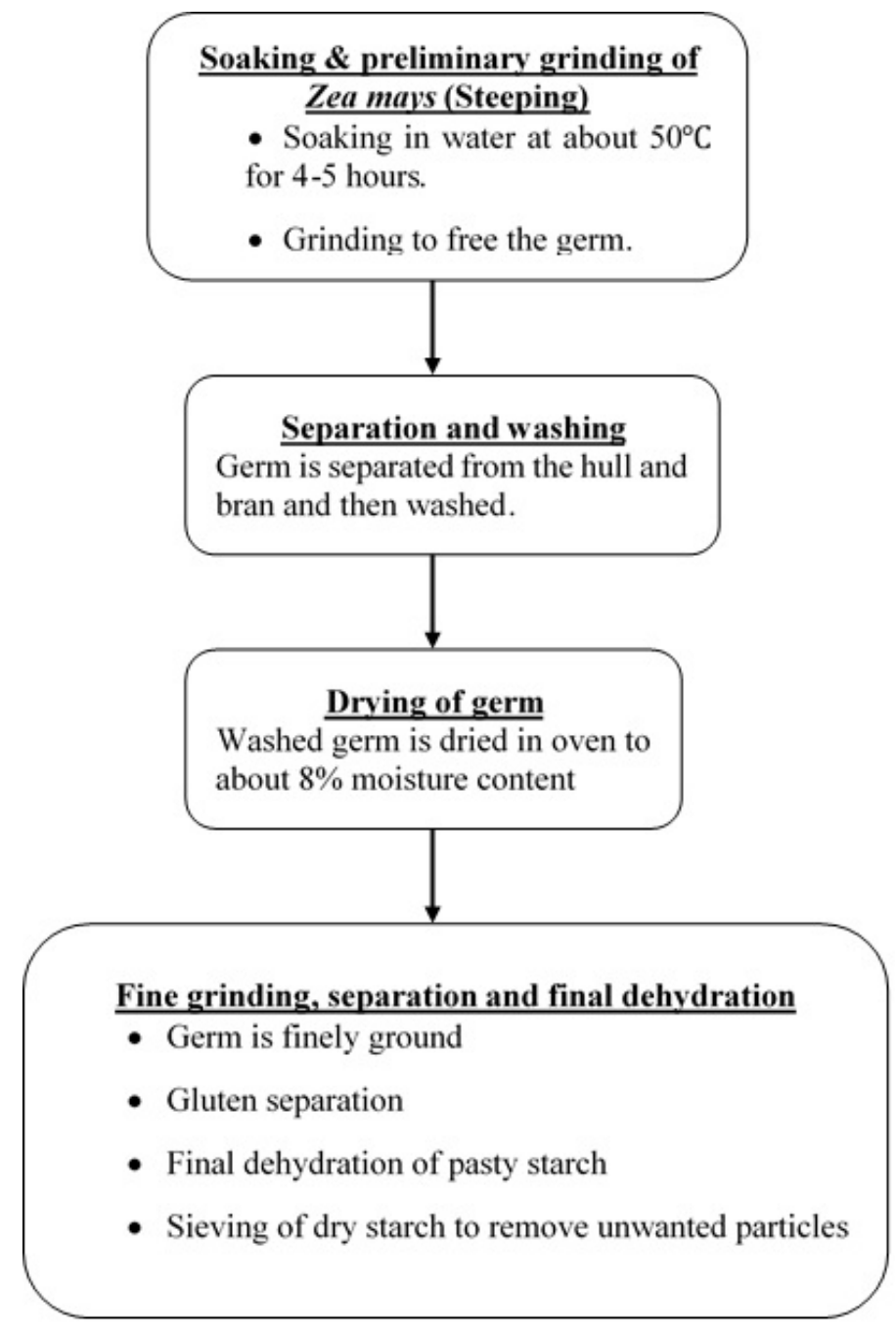

Figure 1. Flow chart for Zea mays starch production

\section{Plastic blend production}

One percent $(1 \%)$ concentration of glycerol was produced by diluting $10 \mathrm{ml}$ of pure glycerol with $1000 \mathrm{ml}$ of distilled water as plasticizer. The crucibles were prepared by coating them with coconut oil to avoid sticking of polymer blend to the surface of the crucibles. A total of 6 sample blends containing $5 \%, 10 \%, 15 \%$, $20 \%, 40 \%$ and $50 \%$ by weight of Zea mays starch was prepared by weighing LDPE and the prepared starch using the OHAUS digital weighing scale (Model PA214). The weighed LDPE and starch were mixed with the glycerol (plastici-zer) for each percentage composition, as shown in Table1. These mixtures were poured into the prepared crucible as well as allowed to melt and blend properly by mechanically stirring at temperatures above $120^{\circ} \mathrm{C}$. The molten polymer blends were then poured on aluminium foil and allowed to cure at room temperature $\left(25^{\circ} \mathrm{C}\right)$ for 24 hours. This procedure was repeated for all 6 blend formulations as shown in Table 1. A pure LDPE sample (i.e. $100 \%$ LDPE), which served as the control sample, was also prepared as well. Each produced polymer blend was weighed using the OHAUS digital weighing scale (Model PA214) to determine the initial weight.

Table 1. LDPE/Zea mays starch formulations

\begin{tabular}{|c|c|c|}
\hline Sample name & LDPE (wt.\%) & $\begin{array}{c}\text { Zea mays starch } \\
\text { (wt.\%) }\end{array}$ \\
\hline 5 CoS & 95 & 5 \\
\hline 10 CoS & 90 & 10 \\
\hline 15 CoS & 85 & 15 \\
\hline $20 \mathrm{CoS}$ & 80 & 20 \\
\hline $40 \mathrm{CoS}$ & 60 & 40 \\
\hline $50 \mathrm{CoS}$ & 50 & 50 \\
\hline
\end{tabular}

Note: CoS - Zea mays starch 


\section{Biodegradation analysis}

The weighed samples were buried in sandy loam soil at a depth of about $10.16 \mathrm{~cm}$ (4 in.) for a period of 28 days in an uncontrolled environment. The biodegradation of the polymer blend samples was monitored by excavating them from the soil every seven days for a period of four weeks and the degradation was calculated by measuring the weight loss per week using equation 1 . This method is commonly known as "degradation by weight loss" (Yang et al., 2006; Dong et al., 2008; Maryam and Hadi, 2016; Mostafa et al., 2018). This procedure was repeated for all the produced samples for this period of time.

$$
D=\frac{w_{0}-w_{1}}{w_{0}} \times 100 \%
$$

Where $D=$ Degradation Ratio (\%)

$$
w_{0}=\text { initial weight }(\mathrm{g})
$$$$
w_{1}=\text { current weight }(\mathrm{g})
$$

The degradation rate was determined using equations 2 and 3 for all the buried samples for the given period. The degradation rate was calculated by finding the instantaneous degradation ratios as follows:

$$
D_{i}=\frac{w_{x}-w_{y}}{w_{x}} \times 100 \%
$$

$$
D_{t}=\frac{D_{i}}{N}
$$

Where $D_{i}=$ [Instantaneous Deg] radation Ratios

$w_{x}=$ Former weight

$w_{y}=$ New weight

$D_{t}=$ Degradation Rate (\% per day)

$\mathrm{N}=$ Number of days

\section{RESULTS AND DISCUSSION}

The result of particle sizes classification is shown in Table 2. The particle size, organic matter composition and salinity analysis indicates that the soil where the biodegradable samples were buried corresponded to Loamy Sand.

The results of the biodegradation ratio and biodegradation rates for the $6 \mathrm{LDPE} /$ Zea mays blends are shown in Figures 2 to 7.

Figure 2 shows a relatively steady increase in weekly degradation ratio for sample $5 \mathrm{CoS}$. Degradation by $10.73 \%$ occurs after 7 days, $17.94 \%$ after 14 days, $23.03 \%$ after 21 days and then finally by $27.08 \%$ after 28 days. Conversely, degradation rate for $5 \mathrm{CoS}$ saw a decline from $1.53 \%$ per day during the first week to $1.15 \%$ per day during the second week then $0.89 \%$ the third week and finally $0.75 \%$ in the final week.

For sample $10 \mathrm{CoS}$, Figure 3 shows that degradation ratio increased rapidly for the first three

Table 2. Soil sample analysis

\begin{tabular}{|c|c|c|c|c|c|c|c|}
\hline Soil Depth & Organic Matter & Salinity & Sand & Slit & Clay & pH Value & Textural Class \\
\hline $10.16 \mathrm{~cm}$ & 35.65 & 1.05 & 75.68 & 5.80 & 18.52 & 4.20 & Loamy Sand \\
\hline
\end{tabular}



Figure 2. Biodegradation ratios and rate of $5 \mathrm{CoS}$ 


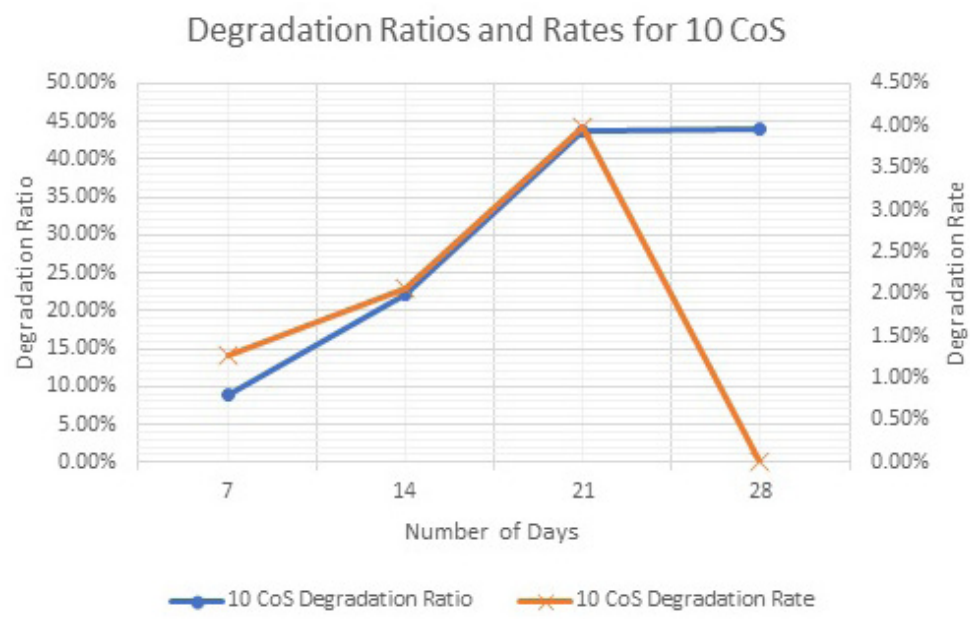

Figure 3. Biodegradation ratios and rate of $10 \mathrm{CoS}$

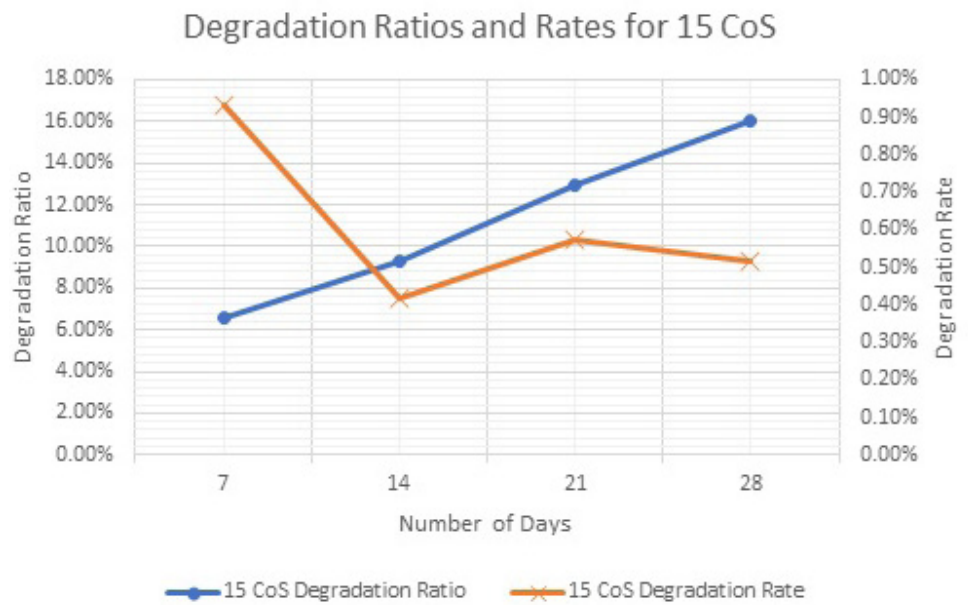

Figure 4. Biodegradation ratios and rate of $15 \mathrm{CoS}$

weeks; $8.91 \%, 22.12 \%$ and $43.87 \%$; then $43.94 \%$ degradation ratio was recorded after the fourth week. However, the values obtained for the degradation rate was erratic. An increase in the degradation rate per day for the first $(1.27 \%)$, second $(2.07 \%)$ and third $(3.99 \%)$ weeks was noted, then a large decrease occurred during the fourth $(0.02 \%)$ week.

According to the plot in Figure 4, sample $15 \mathrm{CoS}$ showed relatively lower, but steadily increasing values for degradation ratio: $6.54 \%$ for the first week, $9.72 \%$ the second week, $12.91 \%$ the third and finally $16.07 \%$ after 28 days. The degradation rate for $15 \mathrm{CoS}$ followed a more erratic (zig-zag) pattern than $10 \mathrm{CoS} ; 0.93 \%$, $0.42 \%, 0.57 \%$ and $0.52 \%$ during the first to fourth weeks, respectively.

In Figure 5, it can be seen that there is another steady increase in the degradation ratio of sample 20
CoS over four weeks $-4.27 \%, 5.76 \%, 6.83 \%$ and $7.47 \%$. Conversely, average degradation rates per day: $0.61 \%, 0.22 \%, 0.16 \%$ and $0.10 \%$, decreased steadily for the first to fourth weeks, respectively.

The degradation ratios and rates for sample $40 \mathrm{CoS}$ are presented on the chart in Figure 6. It reveals another steady increase in the degradation ratio - $29.15 \%, 50.97 \%, 68.08 \%$ and $75.41 \%$. The highest values for the degradation rate per day were recorded for this sample. The values were also close together $-4.16 \%, 4.40 \%$, $4.99 \%$ and $3.28 \%$.

Figure 3.6 indicates that the degradation ratio of sample $50 \mathrm{CoS}$ had an increasing pattern similar to the other samples. $13.77 \%, 23.23 \%$, $32.64 \%$ and $40.89 \%$ after the first, second, third and fourth weeks, respectively. The degradation rates per day were relatively close together $1.97 \%, 1.57 \%, 1.75 \%$ and $1.75 \%$. 


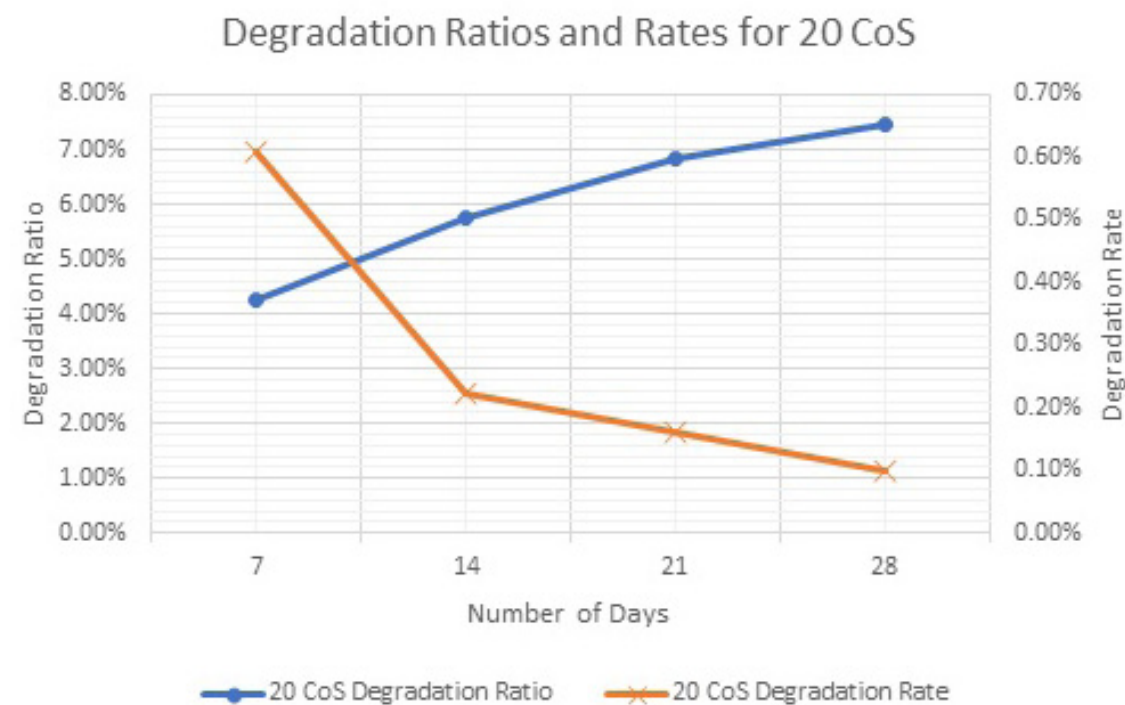

Figure 5. Biodegradation ratios and rate of $20 \mathrm{CoS}$

\section{Degradation Ratios and Rates for $40 \mathrm{CoS}$}



Figure 6. Biodegradation ratios and rate of $40 \mathrm{CoS}$

Figure 8 shows a pattern in the relationship between the biodegradability ratio and biopolymer blend composition recorded for the 6 blends of LDPE/Zea mays; $40 \mathrm{CoS}$ had the highest values for degradability ratio. However, $50 \mathrm{CoS}$ showed the steadiest biodegradation over the four weeks. Almost constant values for biodegradation rate were recorded for $50 \mathrm{CoS}$ (from Figure 7). This implies that under the soil conditions Zea mays/LDPE biopolymer blend was buried and studied, the blend with $50 \%$ LDPE and 50\% Zea mays showed the most optimum biodegradation properties.

\section{CONCLUSION}

All formulated blends have proven to be biodegradable and can be selected for various applications based on the required properties However, the polymer blends with 50\% LDPE (50 CoS) by weight had the most uniform weight loss over the period of the study. Under the given soil conditions, polymer blend $50 \mathrm{CoS}$ also had the steadiest rate of degradation. Hence 50\% LDPE (wt.\%) blended with Zea mays starch is the optimal ratio with regard to the degradability of biopolymer in loamy sand soil of Ota, Ogun State, Nigeria. 


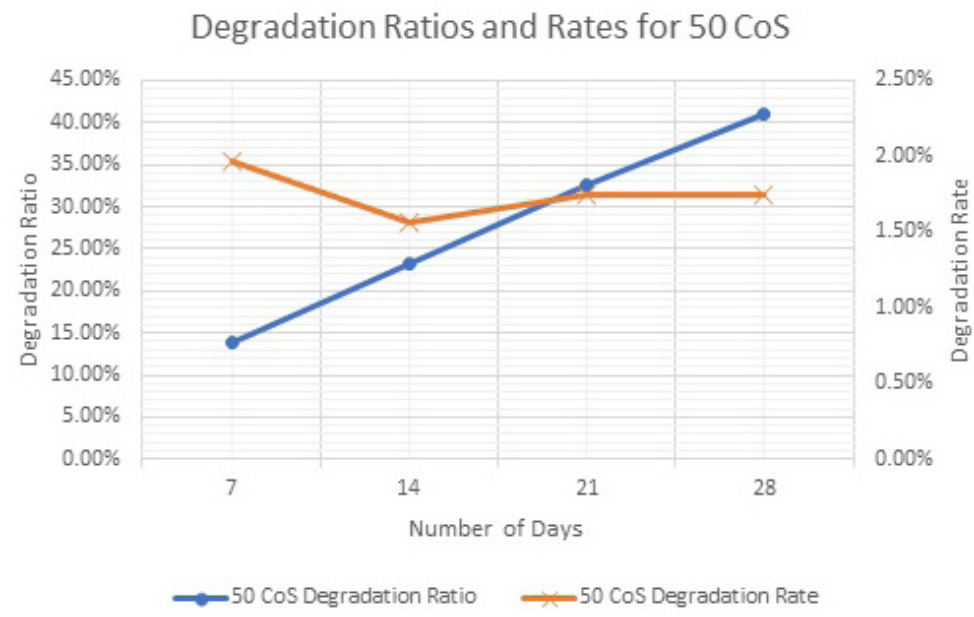

Figure 7 Biodegradation ratios and rate of $50 \mathrm{CoS}$

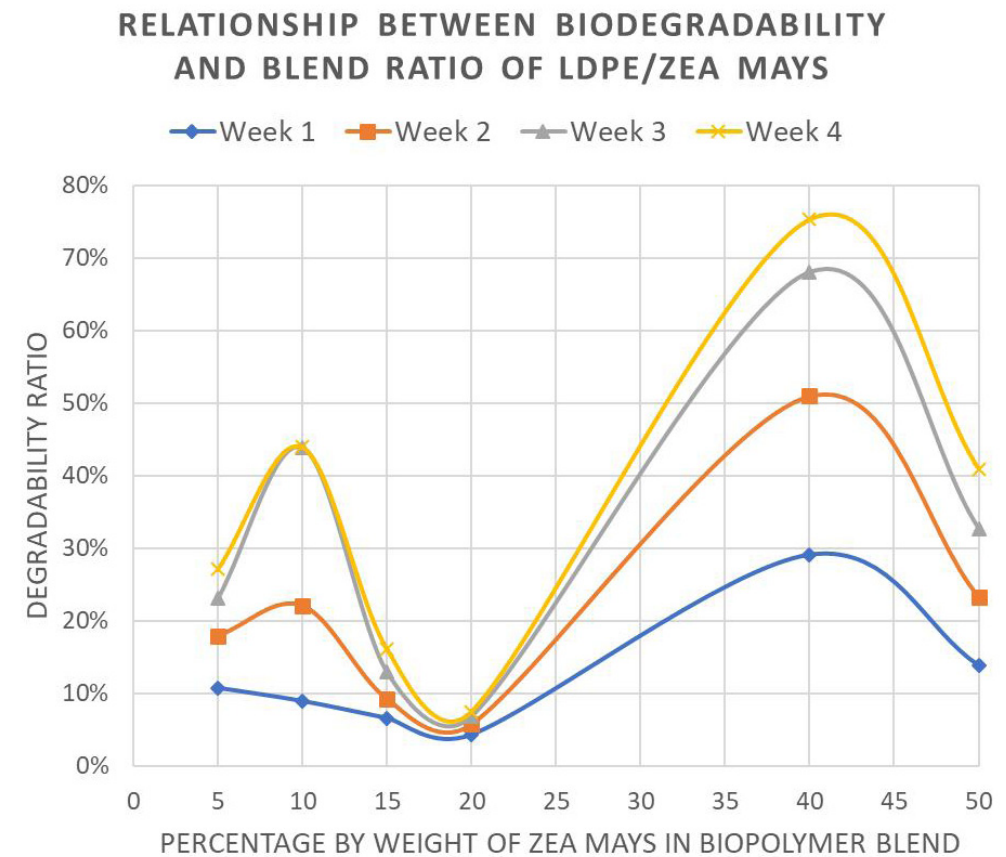

Figure 8. Relationship between biodegradability and blend ratio of LDPE/Zea mays

\section{Acknowledgements}

We acknowledge the financial support offered by Covenant University in actualization of this research work for publication.

\section{REFERENCES}

1. Achi, H.A., Adeofun, C.O., Ufoegbune, G.C., Gbadebo, A.M., Oyedepo, J.A., 2012. Disposal sites and transport route selection using geographic information systems and remote sensing in Abeokuta, Nigeria. Global Journal of Human Social Science Volume 12(12) pp. 14-23.
2. Agwu, M.O., 2012. Issues and challenges of solid waste management practice in Port Harcourt City, Nigeria - A behavioural perspective. American Journal of Social and Management Sciences. Volume 3(2), pp. 83-92.

3. Andrej, K., 2012, Biodegradable Polymers and Plastics, Innovative Value Chain Development for Sustainable Plastics in Central Europe (PLASTiCE), www.plastice.org

4. Axel, S., 2009, Cotton Linters: An Alternative Cellulosic Raw Material, Macromolecular Symposia, Volume 280(1), pp. 45-53

5. Cho, H.S., Moon, H.S., Kim, M., Nam, K., Kim, J.Y., 2011. Biodegradability and biodegradation rate of poly(caprolactone)-starch blend and poly 
(butylene succinate) biodegradable polymer under aerobic and anaerobic environment. Waste Management, 31(3), 475-480. https://doi.org/10.1016/j. wasman.2010.10.029

6. D'Alessandro, N., 2014. 22 Facts about Plastic Pollution. Retrieved March 24, 2018, from https://www. ecowatch.com/22-facts-about-plastic-pollutionand-10-things-we-can-do-about-it-1881885971. html

7. Dong, A.J., Zhang, J.W., Jiang, K., Deng, L.D., 2008. Characterization and in vitro Degradation of Poly (octadecanoic anhydride), Journal of Material Science, 19, 39-46.

8. F.A.O., 2017, The State of Food and Agriculture: Leveraging Food Systems for Inclusive Rural Transformation. www.fao.org/3/a-I7658e.pdf

9. Gilpin, R., Wagel, D., Solch J., 2003. Production, Distribution and Fate of Polycholorinated dibenzop-dioxins, Dibenzofurans and Related Organohalogens in the Environment. In: Dioxins and health (eds A. Schecter \& T. Gasiewicz), 2nd edn. Hoboken, NJ: John Wiley \& Sons Inc.

10. Gregory, M.R., 2009 Environmental Implications of Plastic Debris in Marine Settings-Entanglement, Ingestion, Smothering, Hangers-on, Hitch-hiking and Alien Invasions. Philosophical Transactions of the Royal Society, 364, 2013-2025. (doi: 10.1098/ rstb.2008.0265)

11. Halden, R.U., 2010. Plastics and health risks. Annual Review of Public Health, 31(1), 179-194. [PubMed:20070188].

12. Hoornweg, D. and Bhada-Tata, P., 2012. What a Waste: A Global Review of Solid Waste Management. Urban development series; knowledge papers no. 15. World Bank, Washington, DC. https://openknowledge.worldbank.org/handle/10986/17388.

13. Hopewell, J., Dvorak, R., Kosior, E., 2009. Plastics Recycling: Challenges and Opportunities. Philosophical Transactions of the Royal Society B: Biological Sciences, 364(1526), 2115-2126. doi:10.1098/rstb.2008.0311.

14. Igbinomwanhia, D.I. and Ohwovoriole, E.N., 2012. A study of the constraints to residential solid waste management in Benin metropolis, Nigeria. Journal of Emerging Trends in Engineering and Applied Sciences, 3(1), 103-107.

15. Kayode, A.M. and Omole, F.K., 2011. Some socioeconomic factors affecting solid wastes generation and disposal in Ibadan metropolis, Nigeria. Journal of Environmental Issues and Agriculture in Developing Countries, 1, 55-64.

16. Lamidi, W.A., 2013. Maize (Zea mays) performance at different cultivation systems, Journal of Biology, Agriculture and Health Care, 3(3), 172-182
17. Liverpool-Tasie, S., Omonona, B., Sanou, A., Ogunleye, W., Padilla, S., Reardon, T., 2017. Growth and transformation of food systems in Africa: Evidence from the poultry value chain. Policy Research Brief Vol. 19.

18. Makhtar, N.S.M., Rais, M.F.M., Rodhi, M.N.M., Bujang, N., Musa, M., Hamid, K.H.K., 2013. Tacca leontopetaloides starch: New sources starch for biodegradable plastic. Procedia Engineering, 68, 385-391. doi.org/10.1016/j.proeng.2013.12.196

19. Maryam, H.Y. and Hadi, S.A., 2016. Synthesis, Characterization and Cytotoxicity Study of Poly (ethylene glycol) - HexamethyleneSebacamide Biopolymer. The Iraqi Journal For Mechanical and Material Engineering, Special Volume, Part II, . 442-450

20. Momoh, J.J. and Oladebeye, D.H., 2010. Assessment of awareness, attitude and willingness of people to participate in household solid waste recycling programme in Ado-Ekiti, Nigeria. Journal of Applied Sciences in Environmental Sanitation, 5(1), 93-105.

21. Mostafa, N.A., Awatef, A.F., Hala, M.A., Aghareed, M.T., 2018. Production of Biodegradable Plastic from Agricultural Wastes, Arabian Journal of Chemistry, Volume 11, pp. 546-553

22. Norbert, M.B., Herman, F.M, Norman, G.G., 1968. Encyclopaedia of polymer science and technology: plastics, resins, rubbers, fibres, vol 9, Wiley, New York, pp. 275

23. North, E.J. and Halden, R.U. (2013). Plastics and Environmental Health: The Road Ahead. Reviews on Environmental Health, 28(1), 1-8. http://doi. org/10.1515/reveh-2012-0030.

24. Ofuani, A.I., 2011. Environmental regulation of offshore (E\&P) waste management in Nigeria: How effective? Law, Environment and Development Journal, 7(2), 79-93.

25. Olorunfemi, F.B., 2011. Landfill development and current practices in Lagos metropolis, Nigeria. Journal of Geography and Regional Planning, 4(12), 656-663.

26. Westblad, C., Levendis, Y.A., Richter, H., Howard, J.B., Carlson, J., 2002. A Study on Toxic Organic Emissions from Batch Combustion of Styrene, Chemosphere, 49(4), 395-412 (https://doi.org/10.1016/ S0045-6535(02)00311-9)

27. Yang, J., Webb, A.R., Pickerill, S.J., Hageman G., Ameer, G.A., 2006. Synthesis and Evaluation of Poly (diol citrate) Biodegradable Elastomers. Biomaterials, 27, 1889-1898. 